\title{
Cell Competition and Tumor Heterogeneity
}

\author{
Taylor M. Parker ${ }^{1,2}$, Vanessa Henriques ${ }^{1}$, Antonio Beltran ${ }^{1}$, Harikrishna Nakshatri ${ }^{2,3,{ }^{*},}$, Rajan Gogna ${ }^{1,{ }^{*}}$ \\ ${ }^{1}$ Champalimaud Centre for the Unknown, 1400-038 Lisbon, Portugal; ${ }^{2}$ Departments of Surgery, Biochemistry and \\ Molecular Biology, Indiana University School of Medicine, Indianapolis, IN, 46202, USA; ${ }^{3}$ VA Roudebush Medical Center, \\ Indianapolis, IN 46202, USA
}

*Correspondence to: Rajan Gogna, Ph.D.; Champalimaud Centre for the Unknown, 1400-038 Lisbon, Portugal; Email: rajan.gogna@research.fchampalimaud.org; Phone: +351 210484482, and, Harikrishna Nakshatri, Ph.D.; Department of Surgery, Indiana University School of Medicine, Indianapolis, IN, 46202, USA; Email: hnakshat@iupui.edu; Phone: +13172782238.

\section{ABSTRACT}

Cancers exhibit a remarkable degree of intratumoral heterogeneity (ITH), which results from complex cellular interactions amongst various cell types. This phenomenon provides an opportunity for clonal selection and growth advantages to aggressive cancer cell types, resulting in worse prognosis and challenges to anti-cancer therapy. Cell competition is a conserved mechanism operational in cellular and organ systems, which allows neighboring cells to compare their relative fitness levels and results in the elimination of viable but suboptimal cells. By abuse of this conserved homeostasis mechanism, aggressive cancer cell types gain an advantage over normal cell types by achieving traits like increased proliferation, de-differentiation, and stemness. This review presents recent evidence that cell competition mechanisms actively participate in the regulation of intratumoral cell-cell interactions and thus contribute to $\mathrm{ITH}$, and this process is essential for cancer development and progression.

\section{Classical concepts of cell competition}

Throughout the development and life of an organism, cells are subjected to compromising pressures that impact overall intrinsic health, culminating in viable, but suboptimal cells. Cell competition is an evolutionarily conserved fitness sensing mechanism that functions to ensure optimum tissue health and homeostasis. Neighboring competing cells compare their relative fitness status resulting in the elimination of the suboptimal, less fit cells, "Losers," by the more fit cells, "Winners." Cell competition was first identified in Drosophila by Morata and colleagues through a series of landmark experiments on a class of dominant mutations called Minutes, which encode ribosomal proteins [1]. The homozygous mutation of Minute gene was observed to be lethal, and the heterozygous mutation renders animals viable, but with reduced growth rates and reduced cellular proliferation. Mosaic wing disc studies revealed that although viable on their own, Minute ${ }^{+/-}$clones were eliminated from the disc when surrounded by Minute wildtype cells. These results suggested that competing cells can sense growth rates and that competition results in the elimination of the slower-growing cells. Interestingly, the final wing compartment size was not affected by cell competition, indicating that Minute wildtype clones grew at the expense of mutant clones [2, 3]. Additional investigations revealed that elimination of Minute ${ }^{+/-}$clones by wildtype clones was, in fact, apoptosis dependent [4]. Similar to the Drosophila findings, studies in a chimeric mouse model found that cells with a heterozygous mutation in the ribosomal protein-encoding L24 gene display impaired ribosome biogenesis, and although viable on their own, were eliminated when confronted by wildtype cells [5]. These original findings carved the biological foundation of cell competition, and the most recent decades have uncovered several fitness sensing mechanisms and downstream signaling networks governing competitive interactions. We now understand that cellular fitness is not solely dependent on cell growth or proliferation rates and that multiple complex mechanisms underpin fitness communication and competition. Mechanotransduction, fitness fingerprints, and biochemical signaling are among the identified mechanisms that regulate fitness communication and signaling between Winners and Losers.

In this review, we focus on how cell competition may contribute to tumor heterogeneity. We first describe the general role of cell competition in cancer, with particular focus on p53 and cMyc, two most frequently altered signaling networks in cancer,

This is the author's manuscript of the article published in final edited form as:

Parker, T. M., Henriques, V., Beltran, A., Nakshatri, H., \& Gogna, R. (2019). Cell Competition and Tumor Heterogeneity. Seminars in Cancer

Biology. https://doi.org/10.1016/j.semcancer.2019.09.003 
Parker et. al.

which are also well-known cell competition genes. Several other signaling pathways have been identified which play roles in fitness communication, and downstream apoptotic versus survival signaling; these pathways are also often altered in cancer.

\section{Cell competition and cancer}

Cell competition based cell selection has been shown to regulate oncogenic growth [6], and many of its mechanisms function in sync with oncogenic pathways. As a fitness surveillance mechanism, cell competition may act to repress the early stages of tumorigenesis via effective elimination of mutated, transformed cells by normal, wild-type cells [7-9]. Because of a high degree of phenotypic and genetic diversity, a cancer mass functions as an ecosystem formed by a variety of oncogenic, preoncogenic cells at different stages of evolution. These cells compete in these neoplastic ecosystems to gain maximum proliferation and growth potential amongst themselves and also with the surrounding microenvironment cells. These competitive interactions are now found to be governed by cell competition pathways [10-13]. Thus, the cell competition mechanism allows cells to identify, cooperate, or destroy the surrounding cells based on the survival of the fittest dogma. It was described that cell competition helps in identification and elimination of the viable but suboptimal cells which carry low fitness traits. However, aggressive oncogenic cells can induce death of their surrounding healthy cells, thereby creating space for growth and nutrients for achieving neoplastic transformation. This process has similarity to super competition, first described in fly imaginal discs expressing different doses of $\mathrm{dMyc}$, where cancer cells hijack canonical fitness surveillance and grow at the expense of normal cells, resulting in the formation of cancerous lesions. Transformed cells with supercompetitor phenotype may expand at the expense of the surrounding normal epithelial cells but without inducing any detectable histologic abnormalities. We are presenting a model demonstrating the role of cell competition in the regulation of cancer growth and metastasis (Figure 1).

\section{Role of Myc in the regulation of oncogenic cell pathways}

MYC is one of the most frequently mutated genes and is amplified in a variety of cancers [14]. Taking a specific example of breast cancer (BC), high MYC mRNA and c-Myc protein expression are significantly correlated with worse outcome, poor prognostic factors, hormone therapy resistance, and chemoresistance [15, 16]. Elevated MYC mRNA is associated with Estrogen Receptor negative (ER-) and Progesterone Receptor (PGR)-negative tumors and Triple Negative Breast Cancers (TNBCs). Moreover, although no correlation has been found between c-Myc protein expression and ER, PgR or HER2 status, c-Myc protein is significantly associated with expression of cytokeratin 5/6, EGFR, and other markers of the basal-like phenotype [15]. Regulation of MYC expression in breast cancer is not fully elucidated. MYC is a known estrogen-induced gene [17]. Additionally, MYC is the target of several signaling networks including PI3K/Akt/mTOR, RAS/RAF/MAPK, JAK/STAT, and the Wnt pathway, all of which are identified regulatory pathways in cell competition. In primary TNBCs, MYC was significantly colocalized with cells with stem-like features, including CD44 expression, a marker of stem cells in breast cancer [18]. Moreover, MYC expression is heterogeneous within primary TNBCs as well as TNBC cell lines, and this leads to differences in downstream Myc-regulated genes and ultimately, varying tumorigenic phenotypes within tumors [18]. MYC functions are specific to the molecular subtypes of breast cancer [15]. Interestingly, in ER $\mathrm{BR}^{-} \mathrm{BC}, \mathrm{MYC}$ is associated with the upregulation of several genes involved with glucose metabolism and transport. Among these genes, CACFD1 (Flower), an identified fitness fingerprint involved in cell competition [19], was a centralized signaling hub, indicating the existence of a critical signaling network between MYC and CACFD1 [15]. Since $d M y c$ in a dose-dependent manner has already been shown to confer super competitor phenotype to cells in imaginal discs in drosophila models [20,21], elevated cMyc activity may be one of the mechanisms by which cancer cells acquire similar supercompetitor phenotype, which can also explain for the heterogeneous expression pattern of cMyc in tumors. Dedicated research is warranted to elucidate transcriptional and post-transcriptional $c M y c$ regulatory mechanisms, signaling downstream of $\mathrm{cMyc}$, and relation with cell competition in ER subtypes.

\section{p53 tumor suppressor functions via cell competition mechanisms}

Continuing with the perspective on breast cancer, TP53 is among the top mutated genes in all BC subtypes and mutations in TP53 occur in nearly $80 \%$ of basal-like BCs [22]. In breast cancer, mutations in p53 are associated with more aggressive cases and worse clinical outcome. Loss of heterozygosity in the $p 53$ gene is a frequent occurrence in $\mathrm{BC}$, but nearly $60 \%$ of cases retain a wild-type p53 allele [23]. Even in the absence of p53 mutations, several BC cases subvert p53 activity via exclusion from the nucleus [24] or changes in upstream signaling factors such as the activity of ataxia-telangiectasia (ATM) [25] and Chk2 [26]. Thus, lost or reduced p53 activity via a variety of mechanisms is frequent in BC. Reduced p53 activity has been 
Parker et. al.

found to provide a competitive advantage to cells. In the developing mouse embryo, elevated p53 marks cells as defective and p53 acts upstream to reduce mTOR signaling, which is required for cell proliferation and survival. In co-culture of bone

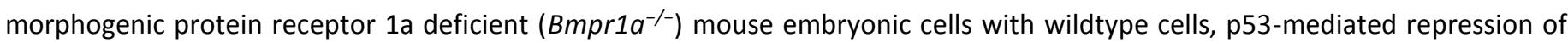
mTOR was observed in the apoptotic Bmp-/- cells [27]. Similarly, it was shown that mild p53 activity in the mouse brain, pancreas, lung, and liver, instead of inducing anticancer responses such as cell cycle arrest or apoptosis contributes to non-cell autonomous cell competition to ensure tissue fitness [28]. Murine double minute (Mdm)2 and Mdm4 negatively regulate p53 and their haploid insufficiency results in mild activation of p53. Mdm2+/-Mdm4+/-double-heterozygous embryonic cells exhibit slightly higher p53 activation than wild-type cells and are thus out-competed, demonstrating its role in the elimination of unfit cells to ensure organ and animal fitness [28]. The hematopoietic stem cells with lower p53 activity dominated the stem cell niche, whereas cells with high p53 activity were forced into senescence [29]. Similarly, a recent study by Watanabe and colleagues found that when Madin-Darby Canine Kidney (MDCK) epithelial cells expressing cancer-enriched p53R273H or p53R175H mutants (gain of function mutations) were surrounded by normal cells, mutant p53 cells underwent necroptosis and were eliminated from the epithelial monolayer by basal extrusion [30]. However, when RasG12V-transformed cells coexpressed mutant p53, necroptosis did not occur. Similar results were obtained in the human pancreatic duct epithelial six (HPDE6) cell line [30]. These results present intriguing evidence that cell competition may play a role in the order of mutation appearance, and thus tumor evolution, by the maintenance or propagating specific clones. In the case of $p 53$, mutations in this gene may occur subsequent to mutations in genes such as Ras such that cells containing mutant p53 loses its loser status and potentially gain winner status. This can also explain for the prevailing view that p53 mutation is a late event in cancer.

\section{Cell competition between tumor and its microenvironment}

It is now well understood that clinically relevant cancer takes several years in development. In this period, there are active competitive interactions between cancer cells and host microenvironment cells [31, 32]. The elimination of the microenvironment cells is crucial for the growth and metastasis of cancer. We present a model of an active cancer-stromal interface in colon, ovarian, pancreatic, and prostate cancer. The cancer tissue must eliminate the stromal tissue to facilitate growth in the affected organ (Figure 2). Evidence of cell competition genes and pathways in the regulation of tumormicroenvironment relations was recently provided from the backdrop of Myc signaling. Immunohistochemical analysis of human colon cancers along the tumor-stroma border revealed that in the presence of c-Myc-expressing tumor cells, stromal cells undergo caspase-dependent apoptosis [33]. Another protein, SPARC, is upregulated in loser cells to provide temporary protection against cell death by inhibiting caspase activity [34]. In cancer, SPARC expression and function appears to be cancerspecific, but select cancers show increased SPARC expression along the tumor-stroma border [35]. Recently the role of Hippo signaling and its downstream transcription factor, Tead, in the regulation of cell competition and fate of fibroblasts was demonstrated [36]. Fibroblasts with genetically suppressed Tead activity behaved as losers and were eliminated when cocultured with wild type cells, whereas increased Tead activity imparted a super-competitor like phenotype to these cells that eliminated wild type cells [36]. This competition axis is very similar to the Yki-Sd and Myc pathway in Drosophila imaginal discs [37, 38]. In cancer, Tead promotes oncogenesis via activation of oncogenic genes, such as CTGF, Cyr61, Myc, and Gli2 [39]. It will be interesting and clinically relevant to analyze the expression of Tead in the tumor-stroma intersections and compare with the central region of the tumor far away from the stroma.

\section{Cell competition between cancer cells within an oncogenic mass}

Elimination of loser cells is accompanied by a concomitant gain in the proliferation of super competitors. An evolving tumor is characterized by robust proliferation of specific populations balanced by senescence and apoptosis of others [40]. For example, injection of the MDA-MB-468 cell line, a triple-negative metastatic breast cancer cell line, into mice results in large tumors with slow growth rates. However, these slow-growing tumors still exhibited high proliferation rates based on robust Ki-67 staining and BrdU incorporation.

Further analysis showed that a select population of cells were apoptotic, indicating that increased proliferation was balanced by apoptosis [41]. This explains an active mechanism for the selection of aggressive or supercompetitive cancer cells from the available pool, which renders cancer more aggressive with time (Figure 3). Thus, cell competition offers a clinically relevant explanation for the growth patterns of human tumors. The critical point to note is the concept of super competitor cells; these are the cells which acquire mutations or activate genetic or signaling pathways which provide them with growth advantages. Here we are describing some of the known mechanisms from cell competition research which might be involved in 
providing cancer cells with such selection advantages. In Drosophila, mutations leading to activation of $d M y c$ [20], and Wg [42] genes and inactivation of Hpo [43], have been reported to confer a supercompetitor status to cells. In mammals inactivating mutations in Hippo [44], and Notch [45], as well as activating mutations in Myc [46] result in supercompetitors. We have recently demonstrated that Flower gene isoform switching is another mechanism of achieving supercompetitor phenotype [47].

\section{Cell competition and tumoral heterogeneity}

Historically, cancer research has focused on cell-autonomous changes which result in aberrant cellular activity summarized as the hallmarks of cancer. However, there is increasing appreciation for how non-cell autonomous factors affect the survival, growth, and proliferation of cancer cells, and thereby their function and contribution to the tumor. A hallmark of cell competition is that relative fitness, rather than absolute, determines Winner versus Loser status. In a tumor, competitive interactions would select for more aggressive clones and subclones at the expense of less fit clones, as well as normal host cells. In this regard, cell competition is analogous to the concept of survival of the fittest, but at the cellular level. Ecological principles have often been integrated into the theoretical frameworks proposed to explain cancer initiation and progression. In the clonal evolution model of cancer, first proposed by Peter Nowell in 1976, tumors originate from a single cell with a genetic mutation that conferred enhanced fitness and subsequent mutations followed throughout the lifespan of cancer [48]. In this model, cancer cells follow Darwinian evolution, and the fate of a clone is governed by survival of the fittest. The inherent genomic instability of cancer cells provides the source of genetic diversity and pressures from the microenvironment drive the selection of fitter cells. We present a model to depict how the fitness of cells in host organs can affect tumor growth and metastasis (Figure 4). Importantly, neither cancer initiation nor progression are static, but are instead highly dynamic processes and thus relative clonal and cellular fitness changes over time. The ever-changing landscape of cancer ultimately generates a heterogeneous tumor with multiple distinct genotypes and phenotypes. This raises the question of how cell-cell interactions shape the tumor population over the realms of space and time and to what extent cell competition actively shapes tumor dynamics.

\section{Common genetic mechanisms regulating cell competition and tumor heterogeneity}

Tumor heterogeneities can be at hierarchical, genomic/molecular, epigenetic, spatial, metabolic, cell cycle, epithelial to mesenchymal transition (EMT), and immune environment levels [49-53]. Spatial heterogeneity may be achieved through either cell competition where dominant clones are expected to drive the extinction of other subclones or interdependence between subclones where paracrine factors, such as growth factors, produced by one clone help the proliferation of the other. This concept has been demonstrated using cancer cells that produce insulin-like growth factor II (IGF-II) and those who do not (IGF-II/- cells). While IGF-II-/-, cells showed a lower proliferation rate than IGF-II+/+ cells when grown separately, in co-culture, IGF-II-/cells grew faster than IGF-II+/+ cells and this increased proliferation was dependent on IGF-II. In this case, cell competition is a controlled process where IGF-II-/- cells are dominant clones, which limit the growth but do not extinguish IGF-II+/+ clones [54]. This type of mutual dependency results in stable heterogeneity. However, as the tumor progresses, the dominant clone may achieve independence from the subclones through the accumulation of additional mutations, signaling pathway activation, and autocrine action of growth factors. For example, in glioblastoma, tumor cells expressing higher levels of Yes-associated protein (YAP) outcompete low-YAP expressing clones to achieve clonal dominance [55]. The master regulator YAP is known to regulate cell competition outcomes, thus establishing links between these processes $[9,56]$. The decision to acquire a dominant or loser clone phenotype may occur immediately after cell division. When proliferating cells complete mitosis, a fraction of newborn daughter cells immediately re-enter the cell cycle, while the remaining cells enter transient or persistent quiescence. Maternally transmitted DNA damage-induced p53 protein or mitogen-induced Cyclin D1 mRNA would determine the cell fate [57]. Those with increased Cyclin D1 would proliferate to become dominant clone over time. This possibly explains why aberration in Cyclin D1 is more common in a variety of cancers [58].

The emmergence of next-generation sequencing technologies, as well as in-depth lineage tracing studies, has provided novel insight into tumor heterogeneity. Whole-genome and exome single-cell sequencing in parallel with single copy profiling in matched normal and tumor single nuclei from an $\mathrm{ER}^{+}$breast cancer and TNBC ductal carcinoma revealed that no two single cancer cells are genetically identical, and both cancer types contained a large number of subclonal and de novo mutations present at low frequencies $(<10 \%)$ [59]. Perhaps these rare subclonal mutations are integral to the different phenotypic responses observed in response to spatial changes in microenvironment pressures, survival from chemotherapy-induced selection sweeps and evasion of immune cells. Single-cell sequencing can identify co-existing genomic changes within a single tumor, thereby delineating tumor heterogeneity at an even higher resolution than bulk tumor sequencing. The combination of 
Parker et. al.

bulk tumor analysis and single-cell analysis reveals clonal evolution and co-existence of independent genomic populations at the single-cell level. Recently, single-cell whole-genome sequencing of EGFR-amplified glioblastomas identified two distinct oncogenic EGFR variants within one tumor.

Further functional characterizations indicated that overexpression of individual variants in neural stem cells resulted in tumors that differed in growth rates, and sensitivity to various EGFR tyrosine kinase inhibitors [60]. In Drosophila, overexpression of EGFR in combination with miR-8 transforms wing disc epithelial cells into supercompetitors that induce apoptosis in neighboring wild-type cells, followed by engulfment of apoptotic cells, ultimately resulting in neoplasia and metastasis [61]. These results can explain why EGFR mutations/overexpression are highly prevalent in a variety of cancers, as the heterogeneous expression of EGFR variants would theoretically contribute to competition among clones and the eventual emergence of clones that are resistant to EGFR inhibitors.

\section{Impact of cancer-microenvironment competition on tumor heterogeneity}

Clonal heterogeneity and cellular genetic heterogeneity are generated over the lifetime of cancer as a result of a series of genetic and epigenetic alterations. This phenotypic and genotypic heterogeneity generates the possibility for competitive interactions between cancer and host cells as well as between cancer cells. Within a growing tumor, cells must compete for space, nutrients, oxygen, and blood supply. Therefore, the overall fitness of the cell is determined not only by cell-autonomous factors but also by the ability of the cell to respond to and adapt to the tumor microenvironment (TME). Cell-cell interactions can be competitive or cooperative, but the context and outcome strongly depend on the local environment and resource availability. Although not a cancer model, essential lessons in cell-cell interactions can be gained from a recent study using the model adaptive radiation of the bacterium Pseudomonas fluorescens. Herein, authors found that under high resource competition, intraspecies (within-species) competition was associated with increased diversity, but strong interspecific (between-species) competition reduced overall diversification.

Interestingly, weak interspecific competition enhanced intraspecific competition and resulted in higher diversification [62]. Similarly, in a tumor comprised of multiple cell types and clones and subclones, the degree and outcome of competitive interactions would depend on differences in fitness and environmental constraints such as space and resources. Undoubtedly, the spatial heterogeneity of the TME plays vital roles in clonal selection. It is well-established that the TME plays critical roles in tumor growth and metastasis and remains a significant obstacle in cancer treatment. The TME is composed of a heterogeneous population of cells, including fibroblasts, immune cells, endothelial cells, adipocytes, pericytes, as well as extracellular matrix components [63]. Thus far, studies of mammalian cell competition have primarily focused on competitive interactions between epithelial cells, and whether cell competition occurs between cells of non-identical origin remains to be uncovered. In this context, recent work has shown competition between non-epithelial cells such as fibroblasts [44], cardiomyocytes [64], and hematopoietic stem and progenitor cells (HSPCs) [29].

\section{Regulation of EMT by cell competition mechanisms}

There is new evidence elucidating the role of EMT in tumor heterogeneity, therapeutic resistance, and metastasis [53, 65]. EMT is a complex process and is mediated by multiple transcription factor networks, and interestingly many of them are critical regulators of the cell competition mechanisms. Known EMT signaling pathways include Notch, Hedgehog, Hippo, and Wnt [66], all of which are known players in cell competition [67]. While Wnt/ $\beta$-catenin is considered a significant signaling pathway required for the progression of colon cancer, a recent study demonstrated the role of hedgehog-GLI1 signaling (HH-GLI) pathway in conferring winner phenotype to colon cancer stem cells through EMT and promote metastasis [68]. In Drosophila wing mosaics, Wg (Wnt homolog)-unresponsive cells are viable on their own but are eliminated by apoptosis when surrounding by Wg-responsive cells.

Moreover, overactivation of the Wg pathway induced by axin or APC loss triggers apoptosis in neighboring wildtype wing disc cells $[42,69]$. Thus, hyperactive Wnt signaling results in supercompetitor status. Work by DiMeo and colleagues found that tumor formation and lung metastasis were dependent on intact WNT signaling in mouse orthotopic human breast cancer model, and was required for cancer cell renewal and maintenance of dedifferentiated state including expression of Slug and Twist. Additionally, canonical WNT pathway signaling has been shown to induce EMT and enhance cell migration by stabilization of Snail and upregulation of Slug and Twist [70]. Whether Wnt-driven EMT programming is part of its competitive edge remains to be explored. 
The Hippo pathway is a highly conserved signaling pathway that serves as the master regulator of organ size and tissue homeostasis by negatively regulating the function of YAP/TAZ. YAP/TAZ are transcriptional co-activators that positively regulate cell proliferation, cell size, and inhibit apoptosis. [71]. YAP/TAZ has been found to induce EMT in human breast epithelial cells, but their specific target genes were not identified. Work by Christofori and colleagues showed that increased Tead2 expression resulted in enhanced YAP/TAZ nuclear localization and ultimately led to an invasive phenotype [72]. In T47D cell line, an ER ${ }^{+}$ breast cancer cell line, Hippo inactivation was required for Twist-mediated EMT, cancer cell invasion, and endowed cells with cancer stem cell-like properties [73]. Another possibility of altered Hippo pathway signaling is by loss of Scribble (Scrib), a tumor suppressor gene that negatively regulates Hippo downstream signaling. Scrib is required to establish apicobasal polarity and defective apicobasal polarity results in uncontrolled proliferation and acquisition of EMT characteristics [74]. Loss of Scrib has been a well-documented example of mechanotransduction-based cell competition [75-77]. In Drosophila, Scrib has been identified as a downstream target of Fat (Ft) receptor, a protein in the Hippo signaling pathway, and Ft requires Scrib to interact with other Hippo pathway members, to regulate Warts kinase activity and repress activation of Yorkie, a transcriptional coactivator in Hippo signaling [78]. In Drosophila, the growth regulatory functions of Scrib required intact Hippo signaling [78]. In Drosophila imaginal discs, Scrib-/- cells display hyperactivated Yorkie resulting in large neoplasms. However, in mosaic wing discs comprised of both wildtype and Scrib ${ }^{-/}$cells, normal cells suppress Yorkie activation and prevent overproliferation of Scrib ${ }^{-/}$cells. $\mathrm{Scrib}^{-/}$cells are subsequently outcompeted by wild-type cells and undergo JNK-mediated apoptosis [9]. Scrib likely relays similar signaling events related to cell competition in mammalian cells as evident from studies in MDCK cells. Loss of Scribble sensitizes cells to higher densities and co-culture of MDCK-WT with MDCK-scribble- knockdown (KD) compacts scribble KD cells, which eventually undergo apoptosis [77, 79]. Scrib-knockdown does not significantly affect MDCK cells when cultured alone, but when co-cultured with wildtype MDCK cells, Scrib-knockdown cells are highly sensitive to compaction and undergo p53-dependent apoptosis via p53-activation of Rho-associated kinase and p38, the stress kinase [77].

\section{Regulation of Immune by cell competition mechanisms}

Inflammatory processes are linked to breast cancer initiation and progression. Breast cancers frequently display an abundant population of infiltrating lymphocytes as a part of the host immune response to suppress the tumor. However, the tumor is frequently able to evade this immune response. It is important to explore whether this evasion is the result of cancer cells outcompeting specific subtypes of recruited immune cells. Two separate studies have shown that breast cancer cells overexpressing the death ligand, FasL (or CD95L), were found to induce apoptosis in the CD95 ${ }^{+}$stromal cell population [80, 81]. Increased FasL expression was observed in ductal carcinomas and hyperplastic breast tissues, but no expression was observed in healthy tissue. Apoptosis was specifically and predominantly found in the lymphocytic $\mathrm{CD}^{+}$cells as well as in blood vessels and fatty tissue adjacent to the tumor [81]. Moreover, the culture of $C D 95^{+}$infiltrating lymphocytes with breast cancer sections induced apoptosis of the lymphocytes. This observation was reversed upon inhibition of CD95L by CD95-Fc fusion molecule [80]. Whether apoptosis of the immune cells was concomitant to enhanced proliferation of cancer cells remains to be uncovered. Still, these examples of cancer cell-induced elimination of immune cells represent one potential strategy mounted by tumor cells to escape immune surveillance. Cell competition, a homeostatic sensing mechanism, is conceptually very similar to the immune system recognition of "self" from "non-self."

In Drosophila, competition-induced elimination of loser clones is promoted by Toll innate immune signaling. The two crucial cell competition genes Myc and Minute which are required for elimination of the loser cells, both use the related but distinct components of the immune deficiency (IMD) and Toll pathways [82]. The standard features in signaling pathways required for elimination of loser clones are involvement of Spätzle (an extracellular ligand), noncanonical Toll-related receptors (TRRs) and NFkB-induced apoptosis. The elimination of loser cells in Myc-induced cell competition model requires Toll-2, Toll-3, Toll-8, and Toll-9, and activation of Relish. However, elimination of loser cells generated in the Minute mutation model required Toll-3 and Toll-9 along with Dorsal and Dif [82]. These results suggest that the genetic identity between competing cells determines the activated signaling pathways. Secondly, these findings suggest that cell competition is an active mechanism built within the innate immune system to remove less fit cells [82]. Although not experimentally demonstrated, cell competition mechanisms could explain for immune cell heterogeneity in tumors where a dominant tumor clone with a distinct metabolic profile (likely glycolytic) may evade killing by $T$ cells, whereas tumor cells without such metabolic adaptation became a loser clone and eliminated by $T$ cells [83]. The current theory is that dominant clones with higher glycolytic activity express reduced levels of IRF1 and CXCL10 immunostimulatory molecules and thus enabling them to avoid recognition by T-cells. However, we 
Parker et. al.

propose an alternative possibility that cell competition could play a significant role in determining the therapeutic response to cancer immunotherapy and developing assays to identify Winner and Loser tumor clones and competition between cancer cells and immune cells could further increase the success of immunotherapy.

\section{CONCLUSION}

The scope of this article is to bring to light the recent advances made in the field of cell competition, specifically in mammalian research. In recent years, important advances have been made in elucidating the role of cell competition in oncogenesis and metastasis. Clonal dynamics and cell-cell interactions within a heterogeneous tumor remains a significant challenge to fully decode, given the enormous complexity. Herein, we extend the recent findings in cell competition, and elucidation of various pathways, as potential mechanisms governing cell selection and contribution to the heterogeneous tumor space. In addition to playing the role of a tumor suppressor during early stages of cancer initiation, cell competition can drive tumor progression via proposed formation of super competent cancer cells $[10,12]$. The theory postulated that cancerous cells acquire the super-competent phenotype by steadily accumulating genomic aberrations where they can promote the death of surrounding healthy cells and via this process, initiate and promote oncogenesis. Research in recent years has presented strong physiological and genetic evidence in support of this hypothesis. The notable advances include 1) identification of genomic aberrations and signaling networks enriched in winner cells (cMyc, YAP/TAZ, p53 mutation, and other genes discussed in the review); 2) cell competition is not confined to epithelial compartment as completion could occur between cancer cells and stromal cells; 3) cell competition as another mechanism of clonal dominance; and 4) role of cell competition in therapeutic resistance and metastasis. These advances also prepare preliminary steps towards exploring the role of cell competition in the design of anti-cancer therapy options, particularly immunotherapies. For example, results showing that inhibition of cell competition-induced apoptosis in simulated precancerous lesions would result in suspended cell death in surrounding healthy tissue and thus diminished tumorigenesis, are very encouraging [61]. Besides, a sizeable number of genetic targets have been identified to participate in both pro- and anti-cancer competition pathways, and we predict soon their role in the fight against cancer will be explored. Future studies focused on thorough investigations of cell competition pathways in the context of oncogenic signaling are paramount and would open new doors for cancer therapies.

\section{FIGURE LEGENDS}

Fig 1. The illustration on the left describes a model explaining the process through which cell competition promotes tumor growth and metastasis. During the early stages of oncogenesis, cell competition may function as a tumor-promoting mechanism and promotes survival and spread of oncogenic cells. To propagate through the affected organ and form pre-cancerous fields, the cancer cells outcompete the surrounding healthy cells, eliminate them, and in the process, create space and availability of nutrients for their propagation. The illustration on the right describes how at advanced cancer stages, the same principle of competition-dependent elimination of host cells by cancer cells promotes the escape of neoplastic cells from the cancer mass, which results in clinically relevant metastasis.

Fig 2. In this figure, the role of cell competition in tumor growth is illustrated from a detailed analysis of the hematoxylin and eosin (H\&E) stained colon adenocarcinoma, ovarian serous high-grade carcinoma, and pancreatic ductal carcinoma sections. All cancers show the clear tumor and stromal regions which have the potential to compete with each other. The cancer mass appears to be heterogeneous with cells are at different stages. The stromal or microenvironment region is marked and represents its cell populations such as fibroblasts, B cells, T cells, endothelial, and epithelial cells, amongst other cell types. At the bottom, a graphical depiction demonstrates the possible role of cell competition between cancer cells and their surrounding heterogeneous tumor microenvironment. The growth of cancer in the affected organ depends on its ability to create space and availability of nutrients by progressive elimination of the stromal cells throughout cancer life-cycle. Recent literature presents evidence for the role of several genes labeled in the figure, which play a role in determining the outcome of the oncogenic fate. These cell competition associated genes 
determine if the cancer cells will be able to outcompete the stromal cells and propagate or the stromal cells will be able to prevent their elimination and stop cancer growth by mounting localized anti-tumor response.

Fig 3. The model explains the role of intra-tumoral cell competition in enhancing the aggressiveness of cancer over time. The tumoral mass, which comprises of a genetically heterogeneous array of cancer cells continues to gain traits of aggression in patients with passing time. We hypothesize that the cancer cells of multiple lineages carry traits of predetermined or acquired competence-levels and these cancer cells keep comparing their relative fitness levels during the period of co-existence within the tumor mass. The cells with higher competence try and outcompete cells with lower competence and, in this process, continuously strive to conserve and propagate the most aggressive genotypic and phenotypic attributes of cancer. The H\&E section of a pancreatic ductal carcinoma highlights some aggressive cancer cells which as per our hypothesis over time would continue to propagate themselves in this cancer mass, and this might be facilitated by intra-tumoral competition with other cells with lower competence. This hypothesis is presented as a graphic illustration below the H\&E stained slides.

Fig 4. Model 4 presents a plausible scenario highlighting the role of cells in the tumor microenvironment in regulating the ability of cancer cells to form heterogenous pre-cancerous fields. The first case (left): Where the tumor microenvironment cells of multiple origins (as shown in the figure) are with high fitness status or are expressing marks of high competitiveness. These cells encounter a heterogeneous population of cancer cells which try to expand in this tissue space. These cancer cells have three evolutionary battles to fight, $\boldsymbol{a}$ ) selection of most competent cancer cell subtypes amongst all cancer cell populations, $\boldsymbol{b}$ ) selected cancer sub-populations to remain viable by regulating competition-based interactions with the tumor microenvironment cells, and c) selected and viable cancer cell subpopulations to outcompete and eliminate the tumor microenvironment cells in order to gain space and nutrition to form pre-cancerous fields. In the presence of tumor microenvironment cells with high fitness levels, the selected cancer cells lose their other 2 battles, and thus, the organs or host tissues can protect themselves from oncogenic invasions. The second case (right): In a scenario where the tumor microenvironment cells are less fit owing to any physiological or genetic reasons. These tumor microenvironment cells have a significant impact on the regulation of tumor genetic heterogeneity. Here 3 forms of competition battles seem to be unfolding, $\boldsymbol{a}$ ) selection of most competent cancer cell subtypes amongst all cancer cell populations, which converts into a long-term evolutionary process because in this scenario pre-cancerous fields are formed which turn into clinically relevant cancers after a number of years, $\boldsymbol{b}$ ) because tumor microenvironment cells have reduced fitness levels they rarely impact viability and proliferation of most cancer cells. Thus they undergo elimination and provide assistance to the formation of pre-cancerous fields, and c) because fitness is a relative concept, these low-fitness tumor microenvironment cells eliminate any cells which may have poor fitness status but collectively allows all the available cancer sub-populations to thrive and proliferate, resulting in a diversification of the genetic background of the cancer cells constituting the pre-cancerous fields.

\section{ACKNOWLEDGMENT}

We thank Gil Costa for preparation of the models for this manuscript; we thank Antonio Palma and Maria Leonor for help with literature survey. This work was supported by Champalimaud Foundation to RG and Susan G Komen for the Cure SAC110025 to HN.

\section{CONFLICT OF INTEREST}

All authors declare no conflict of interest. 


\section{REFERENCES}

[1] G. Morata, P. Ripoll, Minutes: mutants of drosophila autonomously affecting cell division rate, Dev Biol 42(2) (1975) 211-21.

[2] P. Simpson, Parameters of cell competition in the compartments of the wing disc of Drosophila, Dev Biol 69(1) (1979) $182-93$.

[3] P. Simpson, G. Morata, Differential mitotic rates and patterns of growth in compartments in the Drosophila wing, Dev Biol 85(2) (1981) 299-308.

[4] E. Moreno, K. Basler, G. Morata, Cells compete for decapentaplegic survival factor to prevent apoptosis in Drosophila wing development, Nature 416(6882) (2002) 755-9.

[5] E.R. Oliver, T.L. Saunders, S.A. Tarle, T. Glaser, Ribosomal protein L24 defect in belly spot and tail (Bst), a mouse Minute, Development 131(16) (2004) 3907-20.

[6] E. Madan, R. Gogna, E. Moreno, Cell competition in development: information from flies and vertebrates, Curr Opin Cell Biol 55 (2018) 150-157.

[7] A. Sasaki, T. Nagatake, R. Egami, G. Gu, I. Takigawa, W. Ikeda, T. Nakatani, J. Kunisawa, Y. Fujita, Obesity Suppresses CellCompetition-Mediated Apical Elimination of RasV12-Transformed Cells from Epithelial Tissues, Cell Rep 23(4) (2018) 974-982.

[8] M. Kajita, Y. Fujita, EDAC: Epithelial defence against cancer-cell competition between normal and transformed epithelial cells in mammals, J Biochem 158(1) (2015) 15-23.

[9] C.L. Chen, M.C. Schroeder, M. Kango-Singh, C. Tao, G. Halder, Tumor suppression by cell competition through regulation of the Hippo pathway, P Natl Acad Sci USA 109(2) (2012) 484-489.

[10] R. Gogna, K. Shee, E. Moreno, Cell Competition During Growth and Regeneration, Annu Rev Genet 49 (2015) $697-718$.

[11] E. Madan, R. Gogna, E. Moreno, Cell competition in development: information from flies and vertebrates, Curr Opin Cell Biol 55 (2018) 150-157.

[12] E. Moreno, Is cell competition relevant to cancer?, Nat Rev Cancer 8(2) (2008) 141-7.

[13] A. Di Gregorio, S. Bowling, T.A. Rodriguez, Cell Competition and Its Role in the Regulation of Cell Fitness from Development to Cancer, Dev Cell 38(6) (2016) 621-34.

[14] M. Kalkat, J. De Melo, K.A. Hickman, C. Lourenco, C. Redel, D. Resetca, A. Tamachi, W.B. Tu, L.Z. Penn, MYC Deregulation in Primary Human Cancers, Genes (Basel) 8(6) (2017).

[15] A.R. Green, M.A. Aleskandarany, D. Agarwal, S. Elsheikh, C.C. Nolan, M. Diez-Rodriguez, R.D. Macmillan, G.R. Ball, C. Caldas, S. Madhusudan, I.O. Ellis, E.A. Rakha, MYC functions are specific in biological subtypes of breast cancer and confers resistance to endocrine therapy in luminal tumours, Br J Cancer 114(8) (2016) 917-28.

[16] S.L. Deming, S.J. Nass, R.B. Dickson, B.J. Trock, C-myc amplification in breast cancer: a meta-analysis of its occurrence and prognostic relevance, Br J Cancer 83(12) (2000) 1688-95.

[17] C. Wang, J.A. Mayer, A. Mazumdar, K. Fertuck, H. Kim, M. Brown, P.H. Brown, Estrogen induces c-myc gene expression via an upstream enhancer activated by the estrogen receptor and the AP-1 transcription factor, Mol Endocrinol 25(9) (2011) $1527-38$.

[18] N. Gupta, K. Jung, C. Wu, A. Alshareef, H. Alqahtani, S. Damaraju, J.R. Mackey, S. Ghosh, S. Sabri, B.S. Abdulkarim, G. Bigras, R. Lai, High Myc expression and transcription activity underlies intra-tumoral heterogeneity in triple-negative breast cancer, Oncotarget 8(17) (2017) 28101-28115.

[19] C. Rhiner, J.M. Lopez-Gay, D. Soldini, S. Casas-Tinto, F.A. Martin, L. Lombardia, E. Moreno, Flower forms an extracellular code that reveals the fitness of a cell to its neighbors in Drosophila, Dev Cell 18(6) (2010) 985-98.

[20] E. Moreno, K. Basler, dMyc transforms cells into super-competitors, Cell 117(1) (2004) 117-29.

[21] C. de la Cova, M. Abril, P. Bellosta, P. Gallant, L.A. Johnston, Drosophila myc regulates organ size by inducing cell competition, Cell 117(1) (2004) 107-16. 
[22] D.C. Koboldt, R.S. Fulton, M.D. McLellan, H. Schmidt, J. Kalicki-Veizer, J.F. McMichael, L.L. Fulton, D.J. Dooling, L. Ding, E.R. Mardis, R.K. Wilson, A. Ally, M. Balasundaram, Y.S.N. Butterfield, R. Carlsen, C. Carter, A. Chu, E. Chuah, H.J.E. Chun, R.J. N. Coope, N. Dhalla, R. Guin, C. Hirst, M. Hirst, R.A. Holt, D. Lee, H.Y.I. Li, M. Mayo, R.A. Moore, A.J. Mungall, E. Pleasance, A.G. Robertson, J.E. Schein, A. Shafiei, P. Sipahimalani, J.R. Slobodan, D. Stoll, A. Tam, N. Thiessen, R.J. Varhol, N. Wye, T. Zeng, Y.J. Zhao, I. Birol, S.J.M. Jones, M.A. Marra, A.D. Cherniack, G. Saksena, R.C. Onofrio, N.H. Pho, S.L. Carter, S.E. Schumacher, B. Tabak, B. Hernandez, J. Gentry, H. Nguyen, A. Crenshaw, K. Ardlie, R. Beroukhim, W. Winckler, G. Getz, S.B. Gabriel, M. Meyerson, L. Chin, P.J. Park, R. Kucherlapati, K.A. Hoadley, J.T. Auman, C. Fan, Y.J. Turman, Y. Shi, L. Li, M.D. Topal, X.P. He, H.H. Chao, A. Prat, G.O. Silva, M.D. Iglesia, W. Zhao, J. Usary, J.S. Berg, M. Adams, J. Booker, J.Y. Wu, A. Gulabani, T. Bodenheimer, A.P. Hoyle, J.V. Simons, M.G. Soloway, L.E. Mose, S.R. Jefferys, S. Balu, J.S. Parker, D.N. Hayes, C.M. Perou, S. Malik, S. Mahurkar, H. Shen, D.J. Weisenberger, T. Triche, P.H. Lai, M.S. Bootwalla, D.T. Maglinte, B.P. Berman, D.J. Van den Berg, S.B. Baylin, P.W. Laird, C.J. Creighton, L.A. Donehower, G. Getz, M. Noble, D. Voet, G. Saksena, N. Gehlenborg, D. DiCara, J.H. Zhang, H.L. Zhang, C.J. Wu, S.Y. Liu, M.S. Lawrence, L.H. Zou, A. Sivachenko, P. Lin, P. Stojanov, R. Jing, J. Cho, R. Sinha, R.W. Park, M.D. Nazaire, J. Robinson, H. Thorvaldsdottir, J. Mesirov, P.J. Park, L. Chin, S. Reynolds, R.B. Kreisberg, B. Bernard, R. Bressler, T. Erkkila, J. Lin, V. Thorsson, W. Zhang, I. Shmulevich, G. Ciriello, N. Weinhold, N. Schultz, J.J. Gao, E. Cerami, B. Gross, A. Jacobsen, R. Sinha, B.A. Aksoy, Y. Antipin, B. Reva, R.L. Shen, B.S. Taylor, M. Ladanyi, C. Sander, P. Anur, P.T. Spellman, Y.L. Lu, W.B. Liu, R.R.G. Verhaak, G.B. Mills, R. Akbani, N.X. Zhang, B.M. Broom, T.D. Casasent, C. Wakefield, A.K. Unruh, K. Baggerly, K. Coombes, J.N. Weinstein, D. Haussler, C.C. Benz, J.M. Stuart, S.C. Benz, J.C. Zhu, C.C. Szeto, G.K. Scott, C. Yau, E.O. Paul, D. Carlin, C. Wong, A. Sokolov, J. Thusberg, S. Mooney, S. Ng, T.C. Goldstein, K. Ellrott, M. Grifford, C. Wilks, S. Ma, B. Craft, C.H. Yan, Y. Hu, D. Meerzaman, J.M. Gastier-Foster, J. Bowen, N.C. Ramirez, A.D. Black, R.E. Pyatt, P. White, E.J. Zmuda, J. Frick, T. Lichtenberg, R. Brookens, M.M. George, M.A. Gerken, H.A. Harper, K.M. Leraas, L.J. Wise, T.R. Tabler, C. McAllister, T. Barr, M. Hart-Kothari, K. Tarvin, C. Saller, G. Sandusky, C. Mitchell, M.V. Iacocca, J. Brown, B. Rabeno, C. Czerwinski, N. Petrelli, O. Dolzhansky, M. Abramov, O. Voronina, O. Potapova, J.R. Marks, W.M. Suchorska, D. Murawa, W. Kycler, M. Ibbs, K. Korski, A. Spychala, P. Murawa, J.J. Brzezinski, H. Perz, R. Lazniak, M. Teresiak, H. Tatka, E. Leporowska, M. Bogusz-Czerniewicz, J. Malicki, A. Mackiewicz, M. Wiznerowicz, X.V. Le, B. Kohl, N.V. Tien, R. Thorp, N.V. Bang, H. Sussman, B.D. Phu, R. Hajek, N.P. Hung, V.T.P. Tran, H.Q. Thang, K.Z. Khan, R. Penny, D. Mallery, E. Curley, C. Shelton, P. Yena, J.N. Ingle, F.J. Couch, W.L. Lingle, T.A. King, A.M. Gonzalez-Angulo, G.B. Mills, M.D. Dyer, S.Y. Liu, X.L. Meng, M. Patangan, F. Waldman, H. Stoppler, W.K. Rathmell, L. Thorne, M. Huang, L. Boice, A. Hill, C. Morrison, C. Gaudioso, W. Bshara, K. Daily, S.C. Egea, M.D. Pegram, C. Gomez-Fernandez, R. Dhir, R. Bhargava, A. Brufsky, C.D. Shriver, J.A. Hooke, J.L. Campbell, R.J. Mural, H. Hu, S. Somiari, C. Larson, B. Deyarmin, L. Kvecher, A.J. Kovatich, M.J. Ellis, T.A. King, H. Hu, F.J. Couch, R.J. Mural, T. Stricker, K. White, O. Olopade, J.N. Ingle, C.Q. Luo, Y.Q. Chen, J.R. Marks, F. Waldman, M. Wiznerowicz, R. Bose, L.W. Chang, A.H. Beck, A.M. Gonzalez-Angulo, T. Pihl, M. Jensen, R. Sfeir, A. Kahn, A. Chu, P. Kothiyal, Z.N. Wang, E. Snyder, J. Pontius, B. Ayala, M. Backus, J. Walton, J. Baboud, D. Berton, M. Nicholls, D. Srinivasan, R. Raman, S. Girshik, P. Kigonya, S. Alonso, R. Sanbhadti, S. Barletta, D. Pot, M. Sheth, J.A. Demchok, K.R.M. Shaw, L.M. Yang, G. Eley, M.L. Ferguson, R.W. Tarnuzzer, J.S. Zhang, L.A.L. Dillon, K. Buetow, P. Fielding, B.A. Ozenberger, M.S. Guyer, H.J. Sofia, J.D. Palchik, C.G.A. Network, Comprehensive molecular portraits of human breast tumours, Nature 490(7418) (2012) 61-70.

[23] A.M. Davidoff, P.A. Humphrey, J.D. Iglehart, J.R. Marks, Genetic basis for p53 overexpression in human breast cancer, Proc Natl Acad Sci U S A 88(11) (1991) 5006-10.

[24] U.M. Moll, G. Riou, A.J. Levine, Two distinct mechanisms alter p53 in breast cancer: mutation and nuclear exclusion, Proc Natl Acad Sci U S A 89(15) (1992) 7262-6.

[25] S. Angele, I. Treilleux, P. Taniere, G. Martel-Planche, M. Vuillaume, C. Bailly, A. Bremond, R. Montesano, J. Hall, Abnormal expression of the ATM and TP53 genes in sporadic breast carcinomas, Clin Cancer Res 6(9) (2000) 3536-3544.

[26] D.W. Bell, J.M. Varley, T.E. Szydlo, D.H. Kang, D.C.R. Wahrer, K.E. Shannon, M. Lubratovich, S.J. Verselis, K.J. Isselbacher, J.F. Fraumeni, J.M. Birch, F.P. Li, J.E. Garber, D.A. Haber, Heterozygous germ line hCHK2 mutations in Li-Fraumeni syndrome, Science 286(5449) (1999) 2528-2531.

[27] S. Bowling, A. Di Gregorio, M. Sancho, S. Pozzi, M. Aarts, M. Signore, M.D. Schneider, J.P. Martinez-Barbera, J. Gil, T.A. Rodriguez, P53 and mTOR signalling determine fitness selection through cell competition during early mouse embryonic development (vol 9, 1763, 2018), Nat Commun 9 (2018).

[28] G. Zhang, Y. Xie, Y. Zhou, C. Xiang, L. Chen, C. Zhang, X. Hou, J. Chen, H. Zong, G. Liu, p53 pathway is involved in cell competition during mouse embryogenesis, Proc Natl Acad Sci U S A 114(3) (2017) 498-503.

[29] T. Bondar, R. Medzhitov, p53-mediated hematopoietic stem and progenitor cell competition, Cell Stem Cell 6(4) (2010) 30922.

[30] H. Watanabe, K. Ishibashi, H. Mano, S. Kitamoto, N. Sato, K. Hoshiba, M. Kato, F. Matsuzawa, Y. Takeuchi, T. Shirai, S. Ishikawa, Y. Morioka, T. Imagawa, K. Sakaguchi, S. Yonezawa, S. Kon, Y. Fujita, Mutant p53-Expressing Cells Undergo Necroptosis via Cell Competition with the Neighboring Normal Epithelial Cells, Cell Rep 23(13) (2018) 3721-3729.

[31] K. Kaminska, C. Szczylik, Z.F. Bielecka, E. Bartnik, C. Porta, F. Lian, A.M. Czarnecka, The role of the cell-cell interactions in cancer progression, J Cell Mol Med 19(2) (2015) 283-96. 
Parker et. al.

[32] S.M. Brady-Kalnay, Molecular mechanisms of cancer cell-cell interactions: cell-cell adhesion-dependent signaling in the tumor microenvironment, Cell Adh Migr 6(4) (2012) 344-5.

[33] S. Di Giacomo, M. Sollazzo, D. de Biase, M. Ragazzi, P. Bellosta, A. Pession, D. Grifoni, Human Cancer Cells Signal Their Competitive Fitness Through MYC Activity, Sci Rep 7(1) (2017) 12568.

[34] M. Portela, S. Casas-Tinto, C. Rhiner, J.M. Lopez-Gay, O. Dominguez, D. Soldini, E. Moreno, Drosophila SPARC is a selfprotective signal expressed by loser cells during cell competition, Dev Cell 19(4) (2010) 562-73.

[35] E. Petrova, D. Soldini, E. Moreno, The expression of SPARC in human tumors is consistent with its role during cell competition, Commun Integr Biol 4(2) (2011) 171-4.

[36] H. Mamada, T. Sato, M. Ota, H. Sasaki, Cell competition in mouse NIH3T3 embryonic fibroblasts is controlled by the activity of Tead family proteins and Myc, J Cell Sci 128(4) (2015) 790-803.

[37] R.M. Neto-Silva, S. de Beco, L.A. Johnston, Evidence for a growth-stabilizing regulatory feedback mechanism between Myc and Yorkie, the Drosophila homolog of Yap, Dev Cell 19(4) (2010) 507-20.

[38] M. Ziosi, L.A. Baena-Lopez, D. Grifoni, F. Froldi, A. Pession, F. Garoia, V. Trotta, P. Bellosta, S. Cavicchi, A. Pession, dMyc functions downstream of Yorkie to promote the supercompetitive behavior of hippo pathway mutant cells, PLoS Genet 6(9) (2010) e1001140.

[39] Y. Zhou, T. Huang, A.S. Cheng, J. Yu, W. Kang, K.F. To, The TEAD Family and Its Oncogenic Role in Promoting Tumorigenesis, Int J Mol Sci 17(1) (2016).

[40] V. Labi, M. Erlacher, How cell death shapes cancer, Cell Death \& Disease 6 (2015).

[41] A. Marusyk, D.P. Tabassum, P.M. Altrock, V. Almendro, F. Michor, K. Polyak, Non-cell-autonomous driving of tumour growth supports sub-clonal heterogeneity, Nature 514(7520) (2014) 54-+.

[42] J.P. Vincent, G. Kolahgar, M. Gagliardi, E. Piddini, Steep differences in wingless signaling trigger Myc-independent competitive cell interactions, Dev Cell 21(2) (2011) 366-74.

[43] R.M. Neto-Silva, S. de Beco, L.A. Johnston, Evidence for a Growth-Stabilizing Regulatory Feedback Mechanism between Myc and Yorkie, the Drosophila Homolog of Yap, Developmental Cell 19(4) (2010) 507-520.

[44] H. Mamada, T. Sato, M. Ota, H. Sasaki, Cell competition in mouse NIH3T3 embryonic fibroblasts is controlled by the activity of Tead family proteins and Myc, J Cell Sci 128(4) (2015) 790-803.

[45] M.P. Alcolea, P.H. Jones, Cell competition: winning out by losing notch, Cell Cycle 14(1) (2015) 9-17.

[46] S. Di Giacomo, M. Sollazzo, D. de Biase, M. Ragazzi, P. Bellosta, A. Pession, D. Grifoni, Human Cancer Cells Signal Their Competitive Fitness Through MYC Activity, Sci Rep-Uk 7 (2017).

[47] E. Madan, C.J. Pelham, M. Nagane, T.M. Parker, R. Canas-Marques, K. Fazio, K. Shaik, Y. Yuan, V. Henriques, A. Galzerano, T. Yamashita, M.A.F. Pinto, A.M. Palma, D. Camacho, A. Vieira, D. Soldini, H. Nakshatri, S.R. Post, C. Rhiner, H. Yamashita, D. Accardi, L.A. Hansen, C. Carvalho, A.L. Beltran, P. Kuppusamy, R. Gogna, E. Moreno, Flower isoforms promote competitive growth in cancer, Nature 572(7768) (2019) 260-264.

[48] P.C. Nowell, The clonal evolution of tumor cell populations, Science 194(4260) (1976) 23-8.

[49] B.C. Prager, Q. Xie, S. Bao, J.N. Rich, Cancer Stem Cells: The Architects of the Tumor Ecosystem, Cell Stem Cell 24(1) (2019) 41-53.

[50] X. Jin, L.J.Y. Kim, Q. Wu, L.C. Wallace, B.C. Prager, T. Sanvoranart, R.C. Gimple, X. Wang, S.C. Mack, T.E. Miller, P. Huang, C.L. Valentim, Q.G. Zhou, J.S. Barnholtz-Sloan, S. Bao, A.E. Sloan, J.N. Rich, Targeting glioma stem cells through combined BMI1 and EZH2 inhibition, Nat Med 23(11) (2017) 1352-1361.

[51] C.T. Hensley, B. Faubert, Q. Yuan, N. Lev-Cohain, E. Jin, J. Kim, L. Jiang, B. Ko, R. Skelton, L. Loudat, M. Wodzak, C. Klimko, E. McMillan, Y. Butt, M. Ni, D. Oliver, J. Torrealba, C.R. Malloy, K. Kernstine, R.E. Lenkinski, R.J. DeBerardinis, Metabolic Heterogeneity in Human Lung Tumors, Cell 164(4) (2016) 681-94.

[52] S. Liu, Y. Cong, D. Wang, Y. Sun, L. Deng, Y. Liu, R. Martin-Trevino, L. Shang, S.P. McDermott, M.D. Landis, S. Hong, A. Adams, R. D'Angelo, C. Ginestier, E. Charafe-Jauffret, S.G. Clouthier, D. Birnbaum, S.T. Wong, M. Zhan, J.C. Chang, M.S. Wicha, Breast cancer stem cells transition between epithelial and mesenchymal states reflective of their normal counterparts, Stem Cell Reports 2(1) (2014) 78-91.

[53] I. Pastushenko, A. Brisebarre, A. Sifrim, M. Fioramonti, T. Revenco, S. Boumahdi, A. Van Keymeulen, D. Brown, V. Moers, S. Lemaire, S. De Clercq, E. Minguijon, C. Balsat, Y. Sokolow, C. Dubois, F. De Cock, S. Scozzaro, F. Sopena, A. Lanas, N. D'Haene, I. Salmon, J.C. Marine, T. Voet, P.A. Sotiropoulou, C. Blanpain, Identification of the tumour transition states occurring during EMT, Nature 556(7702) (2018) 463-468.

[54] M. Archetti, D.A. Ferraro, G. Christofori, Heterogeneity for IGF-II production maintained by public goods dynamics in neuroendocrine pancreatic cancer, Proc Natl Acad Sci U S A 112(6) (2015) 1833-8.

[55] Z. Liu, P.P. Yee, Y. Wei, Z. Liu, Y.I. Kawasawa, W. Li, Differential YAP expression in glioma cells induces cell competition and promotes tumorigenesis, J Cell Sci (2019).

[56] J. Menendez, A. Perez-Garijo, M. Calleja, G. Morata, A tumor-suppressing mechanism in Drosophila involving cell competition and the Hippo pathway, P Natl Acad Sci USA 107(33) (2010) 14651-14656. 
Parker et. al.

[57] H.W. Yang, M. Chung, T. Kudo, T. Meyer, Competing memories of mitogen and p53 signalling control cell-cycle entry, Nature 549(7672) (2017) 404-408.

[58] T. VanArsdale, C. Boshoff, K.T. Arndt, R.T. Abraham, Molecular Pathways: Targeting the Cyclin D-CDK4/6 Axis for Cancer Treatment, Clin Cancer Res 21(13) (2015) 2905-10.

[59] Y. Wang, J. Waters, M.L. Leung, A. Unruh, W. Roh, X.Q. Shi, K. Chen, P. Scheet, S. Vattathil, H. Liang, A. Multani, H. Zhang, R. Zhao, F. Michor, F. Meric-Bernstam, N.E. Navin, Clonal evolution in breast cancer revealed by single nucleus genome sequencing, Nature 512(7513) (2014) 155-+.

[60] J.M. Francis, C.Z. Zhang, C.L. Maire, J. Jung, V.E. Manzo, V.A. Adalsteinsson, H. Homer, S. Haidar, B. Blumenstiel, C.S. Pedamallu, A.H. Ligon, J.C. Love, M. Meyerson, K.L. Ligon, EGFR Variant Heterogeneity in Glioblastoma Resolved through SingleNucleus Sequencing, Cancer Discov 4(8) (2014) 956-971.

[61] T. Eichenlaub, S.M. Cohen, H. Herranz, Cell Competition Drives the Formation of Metastatic Tumors in a Drosophila Model of Epithelial Tumor Formation, Curr Biol 26(4) (2016) 419-27.

[62] S.F. Bailey, J.R. Dettman, P.B. Rainey, R. Kassen, Competition both drives and impedes diversification in a model adaptive radiation, P Roy Soc B-Biol Sci 280(1766) (2013).

[63] M. Wang, J. Zhao, L. Zhang, F. Wei, Y. Lian, Y. Wu, Z. Gong, S. Zhang, J. Zhou, K. Cao, X. Li, W. Xiong, G. Li, Z. Zeng, C. Guo, Role of tumor microenvironment in tumorigenesis, J Cancer 8(5) (2017) 761-773.

[64] N. Munoz-Martin, R. Sierra, T. Schimmang, C.V. del Campo, M. Torres, Myc is dispensable for cardiomyocyte development but rescues Mycn-deficient hearts through functional replacement and cell competition, Development 146(3) (2019).

[65] M.A. Nieto, R.Y. Huang, R.A. Jackson, J.P. Thiery, Emt: 2016, Cell 166(1) (2016) 21-45.

[66] D. Hong, A.J. Fritz, S.K. Zaidi, A.J. van Wijnen, J.A. Nickerson, A.N. Imbalzano, J.B. Lian, J.L. Stein, G.S. Stein, Epithelial-tomesenchymal transition and cancer stem cells contribute to breast cancer heterogeneity, J Cell Physiol 233(12) (2018) 91369144.

[67] R. Levayer, E. Moreno, Mechanisms of cell competition: themes and variations, J Cell Biol 200(6) (2013) 689-98.

[68] F. Varnat, A. Duquet, M. Malerba, M. Zbinden, C. Mas, P. Gervaz, A. Ruiz i Altaba, Human colon cancer epithelial cells harbour active HEDGEHOG-GLI signalling that is essential for tumour growth, recurrence, metastasis and stem cell survival and expansion, EMBO molecular medicine 1(6-7) (2009) 338-51.

[69] S.J. Suijkerbuijk, G. Kolahgar, I. Kucinski, E. Piddini, Cell Competition Drives the Growth of Intestinal Adenomas in Drosophila, Curr Biol 26(4) (2016) 428-38.

[70] T.A. DiMeo, K. Anderson, P. Phadke, C. Fan, C.M. Perou, S. Naber, C. Kuperwasser, A novel lung metastasis signature links Wnt signaling with cancer cell self-renewal and epithelial-mesenchymal transition in basal-like breast cancer, Cancer Res 69(13) (2009) 5364-73.

[71] I.M. Moya, G. Halder, Hippo-YAP/TAZ signalling in organ regeneration and regenerative medicine, Nat Rev Mol Cell Biol 20(4) (2019) 211-226.

[72] M. Diepenbruck, L. Waldmeier, R. Ivanek, P. Berninger, P. Arnold, E. van Nimwegen, G. Christofori, Tead2 expression levels control the subcellular distribution of Yap and Taz, zyxin expression and epithelial-mesenchymal transition, J Cell Sci 127(Pt 7) (2014) 1523-36.

[73] Y. Wang, J. Liu, X. Ying, P.C. Lin, B.P. Zhou, Twist-mediated Epithelial-mesenchymal Transition Promotes Breast Tumor Cell Invasion via Inhibition of Hippo Pathway, Sci Rep 6 (2016) 24606.

[74] J. Lim, J.P. Thiery, Alternative path to EMT: regulation of apicobasal polarity in Drosophila, Dev Cell 21(6) (2011) 983-4.

[75] C. Bras-Pereira, E. Moreno, Mechanical cell competition, Curr Opin Cell Biol 51 (2018) 15-21.

[76] M. Norman, K.A. Wisniewska, K. Lawrenson, P. Garcia-Miranda, M. Tada, M. Kajita, H. Mano, S. Ishikawa, M. Ikegawa, T. Shimada, Y. Fujita, Loss of Scribble causes cell competition in mammalian cells, J Cell Sci 125(Pt 1) (2012) 59-66.

[77] L. Wagstaff, M. Goschorska, K. Kozyrska, G. Duclos, I. Kucinski, A. Chessel, L. Hampton-O'Neil, C.R. Bradshaw, G.E. Allen, E.L. Rawlins, P. Silberzan, R.E. Carazo Salas, E. Piddini, Mechanical cell competition kills cells via induction of lethal p53 levels, Nat Commun 7 (2016) 11373.

[78] S. Verghese, I. Waghmare, H. Kwon, K. Hanes, M. Kango-Singh, Scribble acts in the Drosophila fat-hippo pathway to regulate warts activity, PLoS One 7(11) (2012) e47173.

[79] A. Bove, D. Gradeci, Y. Fujita, S. Banerjee, G. Charras, A.R. Lowe, Local cellular neighborhood controls proliferation in cell competition, Mol Biol Cell 28(23) (2017) 3215-3228.

[80] M. Muschen, C. Moers, U. Warskulat, D. Niederacher, B. Betz, J. Even, A. Lim, R. Josien, M.W. Beckmann, D. Haussinger, CD95 ligand expression in dedifferentiated breast cancer, J Pathol 189(3) (1999) 378-86.

[81] L.S. Gutierrez, M. Eliza, T. Niven-Fairchild, F. Naftolin, G. Mor, The Fas/Fas-ligand system: a mechanism for immune evasion in human breast carcinomas, Breast Cancer Res Tr 54(3) (1999) 245-253.

[82] S.N. Meyer, M. Amoyel, C. Bergantinos, C. de la Cova, C. Schertel, K. Basler, L.A. Johnston, An ancient defense system eliminates unfit cells from developing tissues during cell competition, Science 346(6214) (2014) 1258236. 
[83] T. Cascone, J.A. McKenzie, R.M. Mbofung, S. Punt, Z. Wang, C. Xu, L.J. Williams, Z. Wang, C.A. Bristow, A. Carugo, M.D. Peoples, L. Li, T. Karpinets, L. Huang, S. Malu, C. Creasy, S.E. Leahey, J. Chen, Y. Chen, H. Pelicano, C. Bernatchez, Y.N.V. Gopal, T.P. Heffernan, J. Hu, J. Wang, R.N. Amaria, L.A. Garraway, P. Huang, P. Yang, Wistuba, II, S.E. Woodman, J. Roszik, R.E. Davis, M.A. Davies, J.V. Heymach, P. Hwu, W. Peng, Increased Tumor Glycolysis Characterizes Immune Resistance to Adoptive T Cell Therapy, Cell metabolism 27(5) (2018) 977-987 e4. 
Figure 1: Cell competition between tumor and host cells promotes cancer growth and metastasis
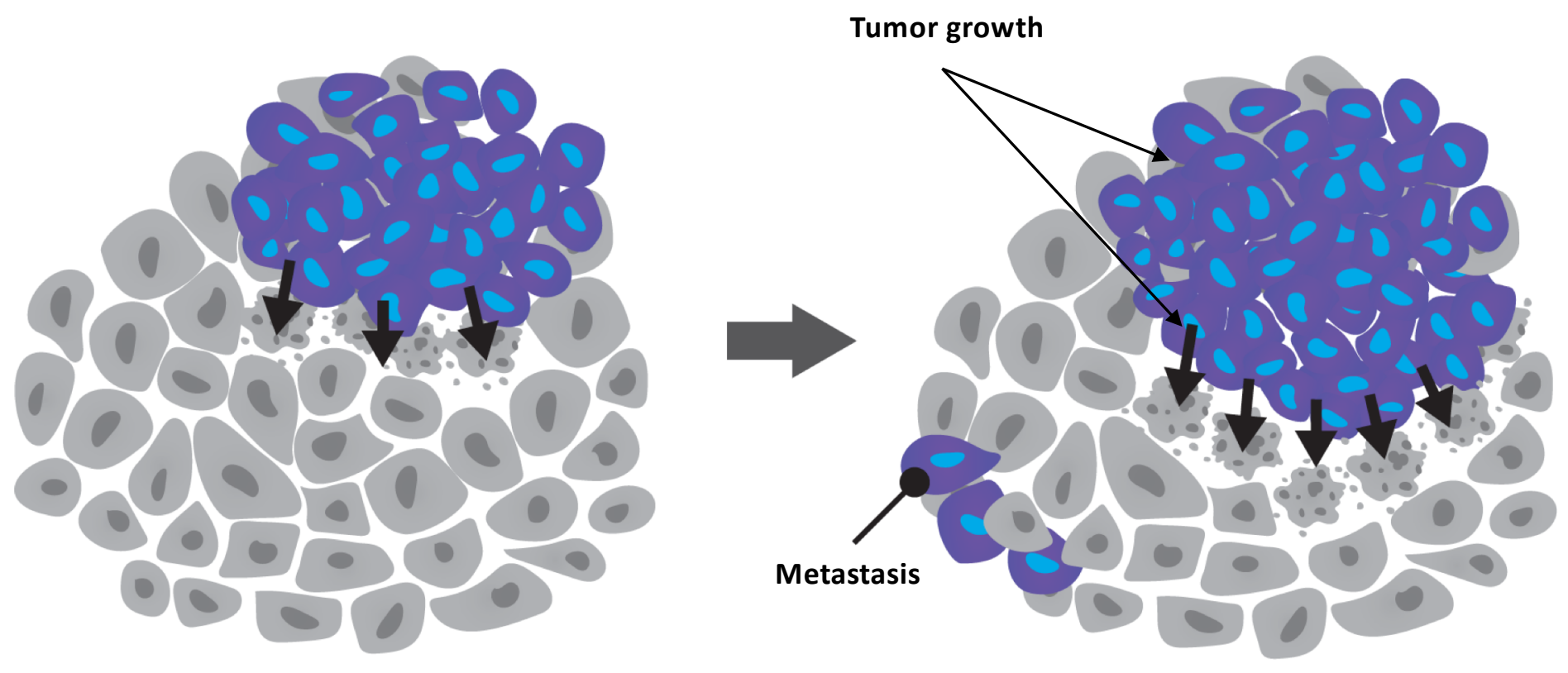

Normal host cells

Elimination of host cells

Tumor cells 


\section{Figure 2: Tumor-stromal interface and complexity of microenvironment in human cancers.}
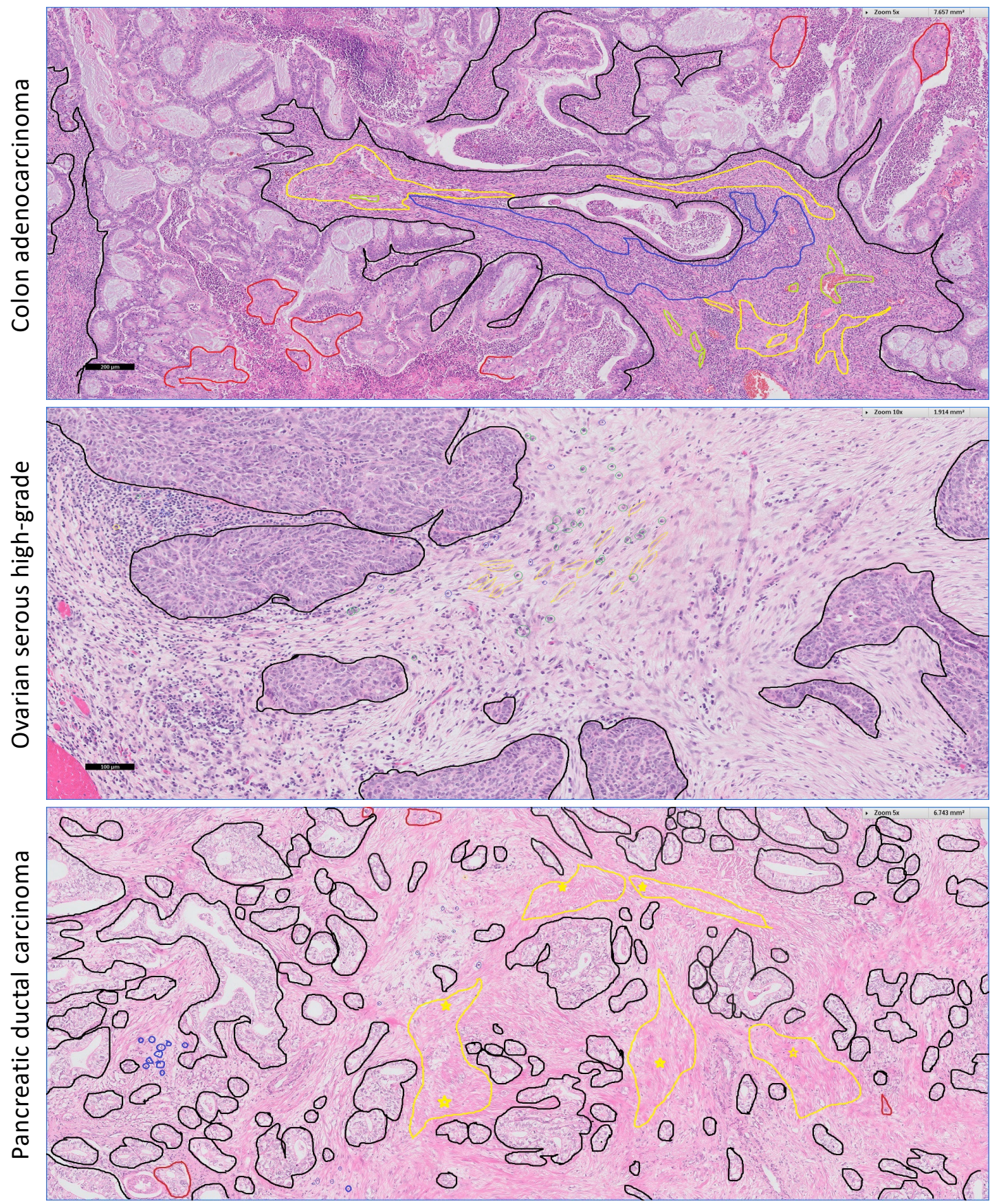

Red markings:

Aggressive cancer cells Black markings:

Tumor/stroma interface Yellow markings:

Fibroblasts

Blue markings:

Lymphocytes

Green markings:

Plasmacytes

Light green markings:

Vessels endothelium

Tumor-stroma interface

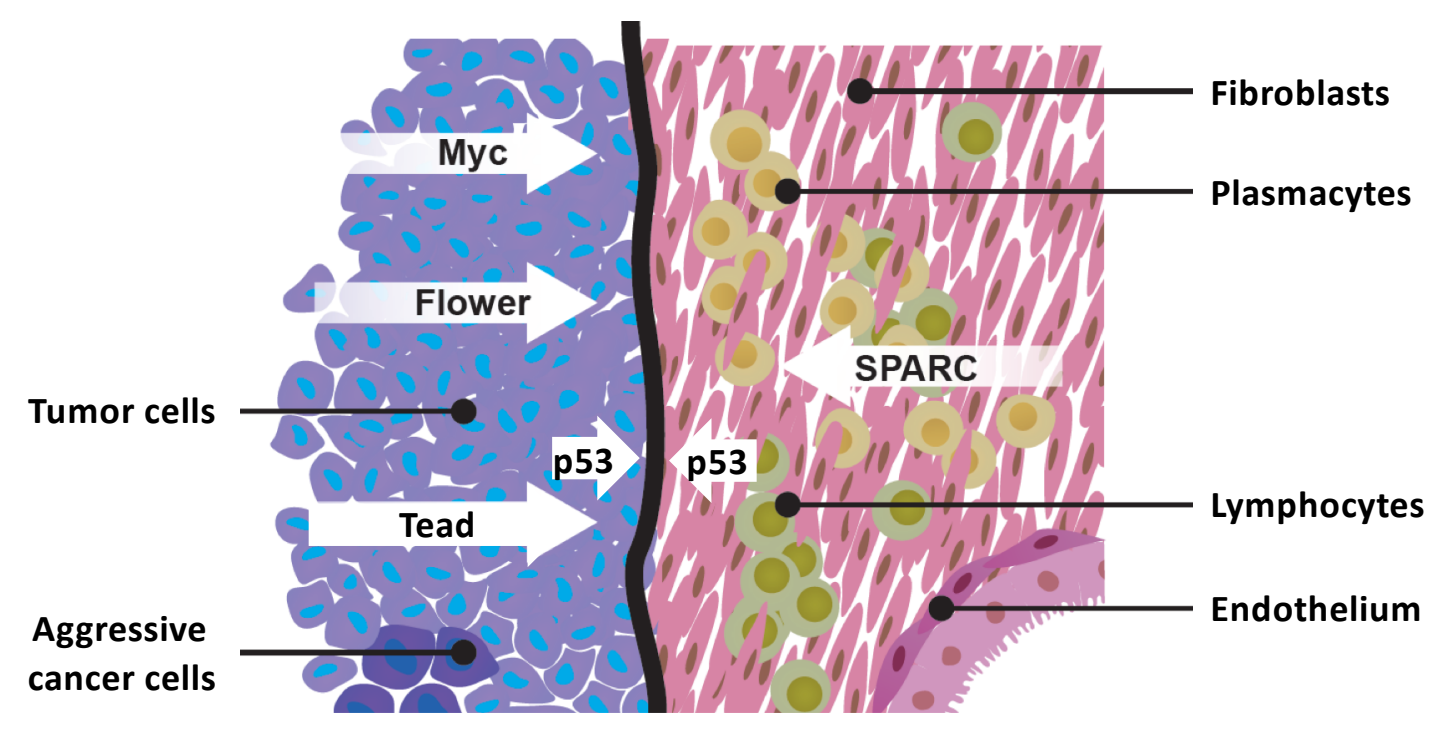


Figure 3: Intra-tumoral cell competition can increase aggressive phenotype of the cancer.

\section{Pancreatic ductal carcinoma}

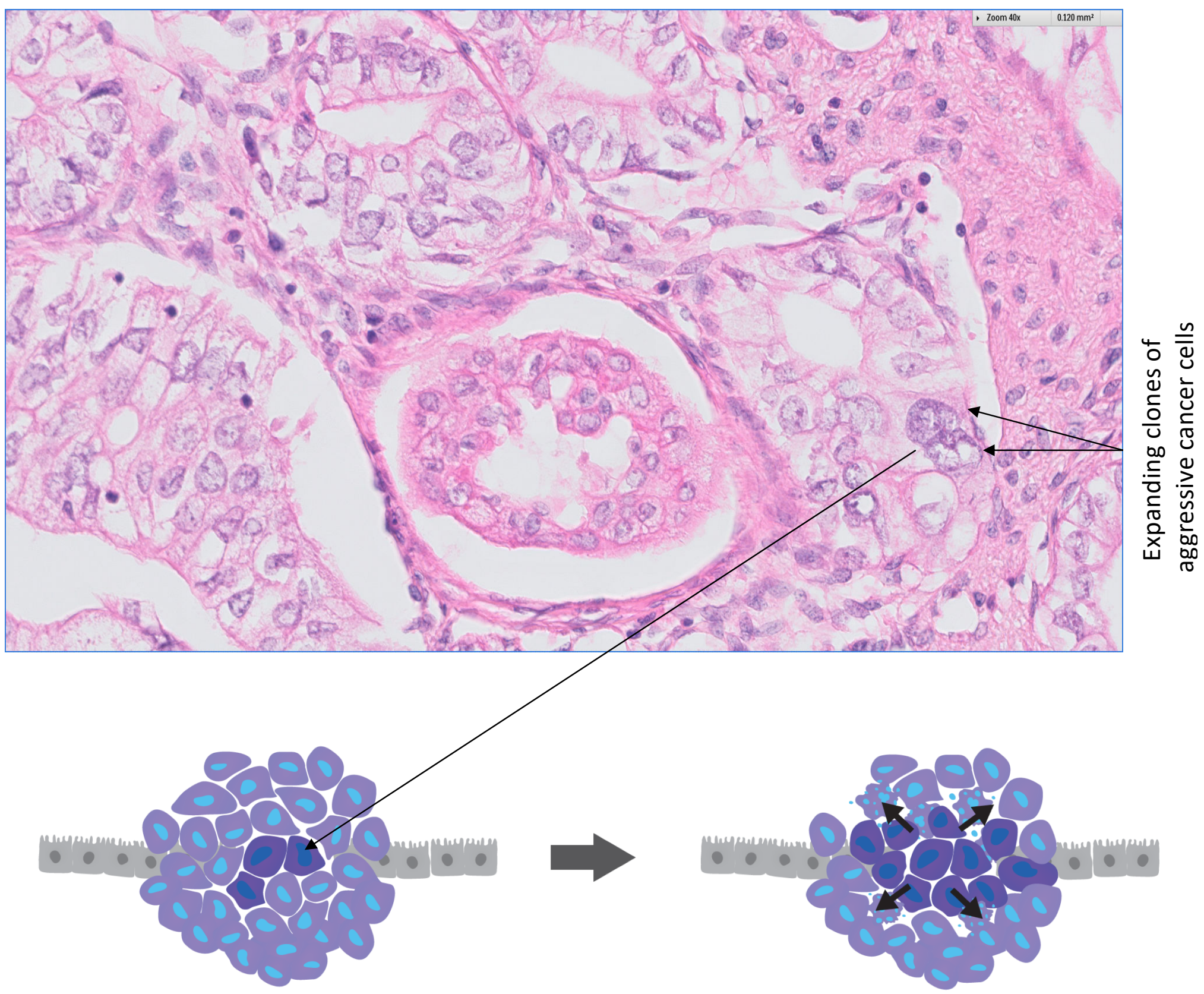

Normal host cells
Less competent tumor cells
Highly competent tumor cells
Elimination of less competent tumor cells 
Figure 4: Fitness of microenvironment determines fate of cancer.
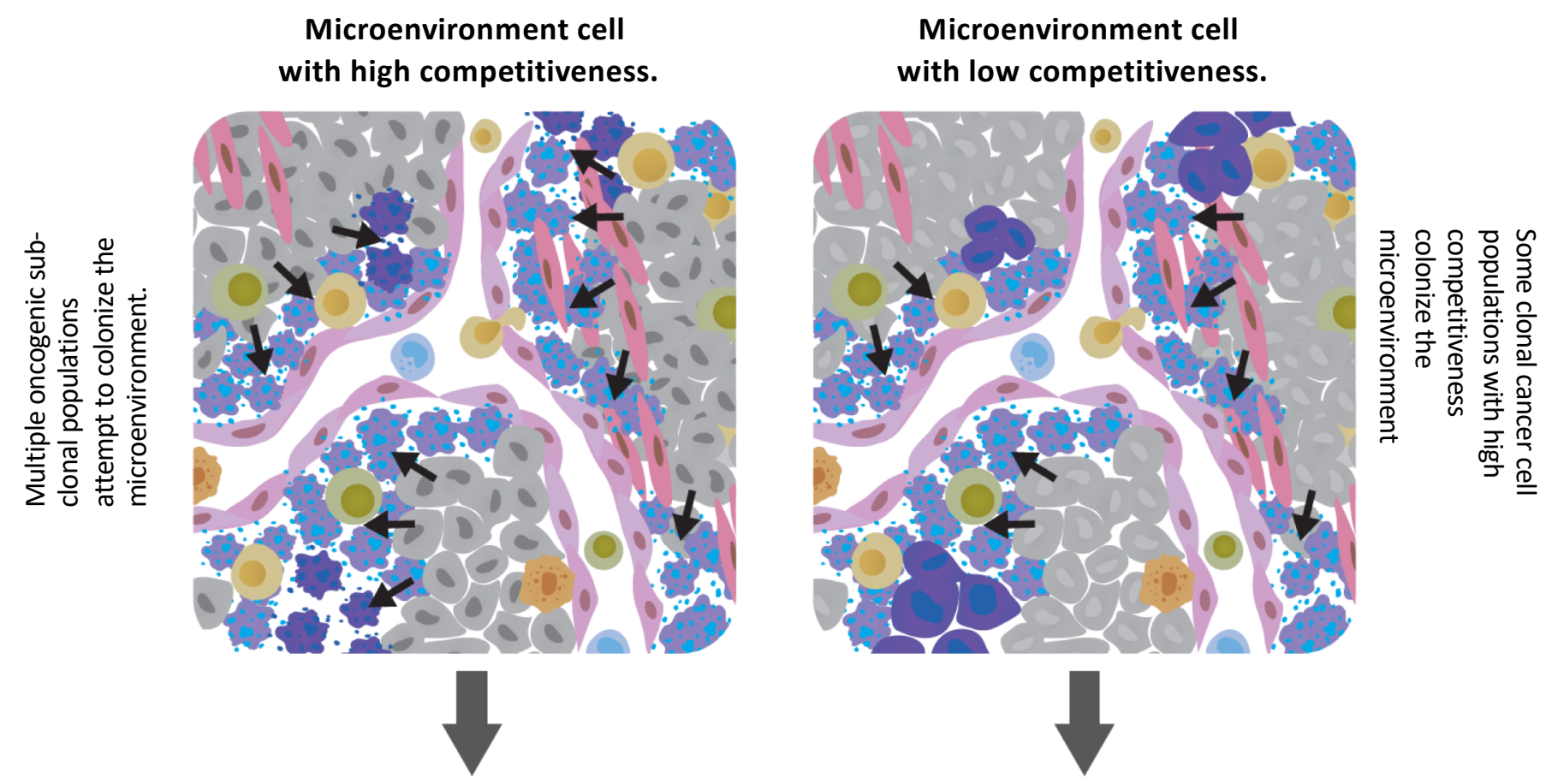

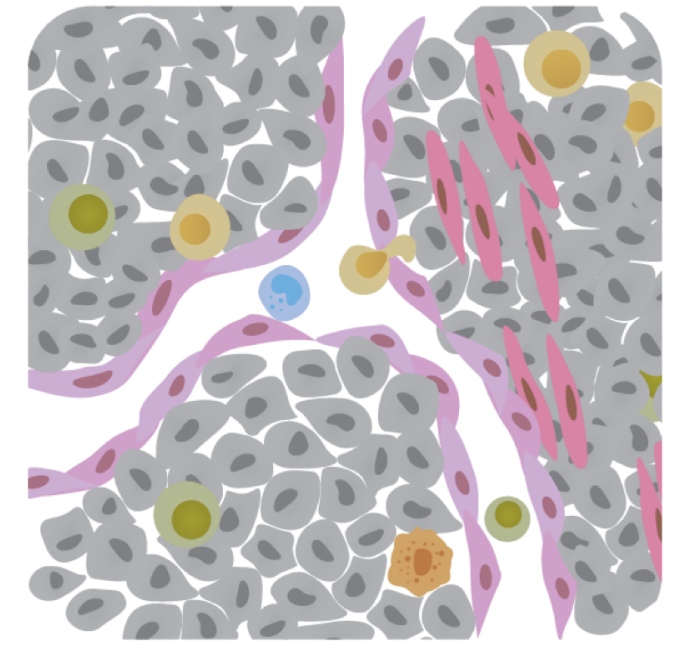

Microenvironment with no cancer

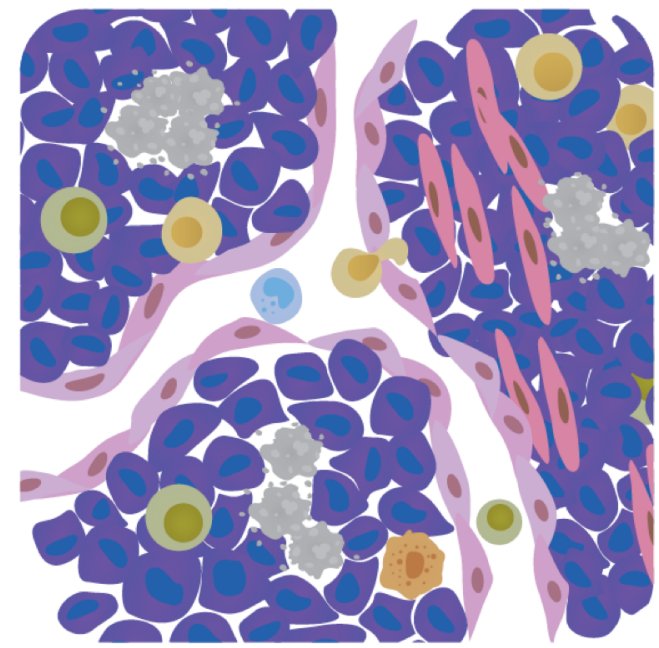

Highly competitive cancer sub-clones which survive colonize

the tumor microenvironment. 